Article

\title{
Response of LUCC on Runoff Generation Process in Middle Yellow River Basin: The Gushanchuan Basin
}

\author{
Caihong Hu, Li Zhang, Qiang Wu, Shan-e-hyder Soomro and Shengqi Jian * \\ School of Water Conservancy Science and Engineering, Zhengzhou University, Zhengzhou 450001, China; \\ hucaihong@zzu.edu.cn (C.H.); leoman1997@gs.zzu.edu.cn (L.Z.); wuqianghlj@163.com (Q.W.); \\ shanhydersoomro110@hotmail.com (S.-e-h.S.) \\ * Correspondence: jiansq@zzu.edu.cn
}

Received: 20 March 2020; Accepted: 21 April 2020; Published: 26 April 2020

\begin{abstract}
Runoff reduction in most river basins in China has become a hotpot in recent years. The Gushanchuan river, a primary tributary of the middle Yellow river, Northern China, showed a significant downward trend in the last century. Little is known regarding the relative contributions of changing environment to the observed hydrological trends and response on the runoff generation process in its watershed. On the basis of observed hydrological and meteorological data from 1965-2010, the Mann-Kendall trend test and climate elasticity method were used to distinguish the effects of climate change and human activities on runoff in the Gushanchuan basin. The results indicate that the runoff in the Gushanchuan Basin has experienced significant declines as large as $77 \%$ from 1965 to 2010, and a mutation point occurred around 1997; the contribution rate of climate change to runoff change is $12.9-15.1 \%$, and the contribution rate of human activities to runoff change is $84.9-87.1 \%$. Then we divided long-term data sequence into two stages around the mutation point, and analyzed runoff generation mechanisms based on land use and cover changes (LUCC). We found that the floods in the Gushanchuan Basin were still dominated by Excess-infiltration runoff, but the proportion in 1965-1997 and 1998-2010 decreased gradually (68.46\% and 45.83\% in turn). The proportion of Excess-storage runoff and Mixed runoff has increased, which means that the runoff is made up of more runoff components. The variation law of the LUCC indicates that the forest area increased by $49.61 \%$, the confluence time increased by $50.42 \%$, and the water storage capacity of the watershed increased by $30.35 \%$.
\end{abstract}

Keywords: runoff generation; Gushanchuan Basin; LUCC; Middle Yellow river

\section{Introduction}

The world's population is increasing rapidly so that the scale of the economy is expanding, and humans are over-interfering with the natural ecosystems. It has resulted in a series of ecological and environmental problems in the Loess Plateau located in the arid and semi-arid regions of the north in China. That is the main problem of soil erosion [1,2]. For a long time, water shortage and soil erosion have become the main sources that restrict the economic development in the Loess Plateau. It is known as "Frequent drought and hardship rank first among the world", and 1/5 of the poverty counties in China are distributed in the Loess Plateau [3]. Vegetation is an important part of soil and water conservation, and it is the core of the ecological environment construction of the Loess Plateau. It is also one of the main ways to restore the ecological decline of the Loess Plateau $[4,5]$. Over the past 50 years, the country has successively implemented a series of ecological construction projects such as key construction of soil and water conservation, construction of the Three-North Shelterbelt Program (TNSP), protection of natural forest resources, returning farmland to forests and grasslands, and construction of silt dams on the Loess Plateau. Most of these major initiatives are 
based on vegetation restoration and reconstruction. All these initiatives are in order to enhance the benign development of regional water cycle and promote the balance of the socio-economic-ecological system. The melioration of soil erosion in the Loess Plateau through vegetation restoration can be divided into two aspects: (1) changing the water circulation path to prevent soil erosion, perennial vegetation can reduce surface runoff by increasing effective vegetation coverage; (2) increasing soil water content and increasing vegetation productivity.

The Loess Plateau in China is the main runoff area of the Yellow River Basin. After the 1980s, the Yellow River water volume showed a notable downward trend [6,7] and the cause of the sharp decline of runoff in the Yellow River has always been the focus of academic debate. Feng [8] pointed out that due to land use and cover changes (LUCC) on the Loess Plateau, its water yield may decline. Besides, with the large-scale vegetation restoration on the Loess Plateau, the flow process is significantly affected, and its impact depends on the vegetation type $[9,10]$. However, Shi [11] found that the contribution rate of climate change to the reduction of runoff in the middle reaches of the Yellow River accounted for more than $40 \%$. The impact of changing environment on runoff is still controversial. Currently, most of the research focuses on quantitative analysis of land use change on the basin's hydrological cycle. This study intends to explore changes in runoff process in typical basins in the middle reaches of the Yellow River from the perspective of runoff generation patterns. Runoff generation, referring to the process of generating various runoff components in the basin. It is essentially the movement and development process of water under the combined effects of various factors on the underlying surface, it is also the redistribution process of rainfall on the underlying surface (ground and aeration zone). Different underlying surface conditions have different runoff generation mechanisms, and different runoff generation mechanisms affect the development of the entire runoff process. It presenting different runoff characteristics. At present, the natural runoff generation mechanism can be divided into four types: Surface runoff $\left(R_{S}\right)$, Saturated ground runoff $\left(R_{s a t}\right)$, Interflow $\left(R_{\text {int }}\right)$ and Underground runoff $\left(R_{g}\right)$ [12-14]. These four classes of runoff mechanisms comprehensively show three phenomena: Excess-infiltration runoff, Excess-storage runoff and Mixed runoff. The Loess Plateau has sparse rainfall, high rainfall intensity, low vegetation coverage, and the thickness of the aerated zone up to tens of meters or even hundreds of meters, which is a typical Excess infiltration runoff area [15].

The Gushanchuan Basin is located in the first sub region of Loess Hilly and gully area, with extremely serious soil erosion and fragile ecological environment. However, the hydrological cycle in this special area still have not been investigated thoroughly. This paper aims to identify the runoff process, and gains insight into the runoff generation mechanism variation to the response of LUCC, based on the quantitative analysis of the impacts of climate change and human activities on runoff in the Gushanchuan Basin. It also tries to seek the cause of the decrease in the amount of runoff in the Yellow River from the perspective of the runoff process, and provide the necessary scientific basis for the effectiveness of ecological construction of the Loess Plateau and the formulation of regional sustainable development countermeasures.

\section{Materials and Methods}

\subsection{Study Area}

Gushanchuan Basin is a primary tributary on the right bank of the middle reaches of the Yellow River in Shaanxi and Inner Mongolia province, China (110 $\left.32^{\prime} 24^{\prime \prime}-111^{\circ} 05^{\prime} 24^{\prime \prime} \mathrm{E}, 39^{\circ} 00^{\prime} 00^{\prime \prime}-39^{\circ} 27^{\prime} 36^{\prime \prime} \mathrm{N}\right)$. Originating from Urigol Township, Inner Mongolia, through the Junggar Banner and Fugu County of Shaanxi Province, and finally flows into the Yellow River near Fugu County, with a drainage area of $1272 \mathrm{~km}^{2}$ (Figure 1). Mean annual precipitation of this basin is about $420 \mathrm{~mm}$, and the interannual variation of rainfall is unevenly distributed. The flood season (June-September) accounts for $80 \%$ of total precipitation. Affected by the semi-arid continental climate in the mid-temperate zone, the basin has long sunshine duration and large evapotranspiration. Short-term heavy rainfall is the main cause of runoff generation in the basin, often causing mountain torrents and severe soil erosion. The geomorphic 
types in the basin are mainly loess hills and gullies, and there are a few loess sand covered areas in the upper reaches. The main soil type is loessial soil, followed by chestnut soil. The soil structure is loose, with great permeability, and it is easy to form the surface runoff. Since the 1970s, a large number of soil and water conservation measures were implemented in the basin, and the land use changed significantly which has affected the characteristics of regional runoff. Therefore, detecting and analyzing the impact of changing environment of Gushanchuan basin can be important to manage water resources in this watershed.

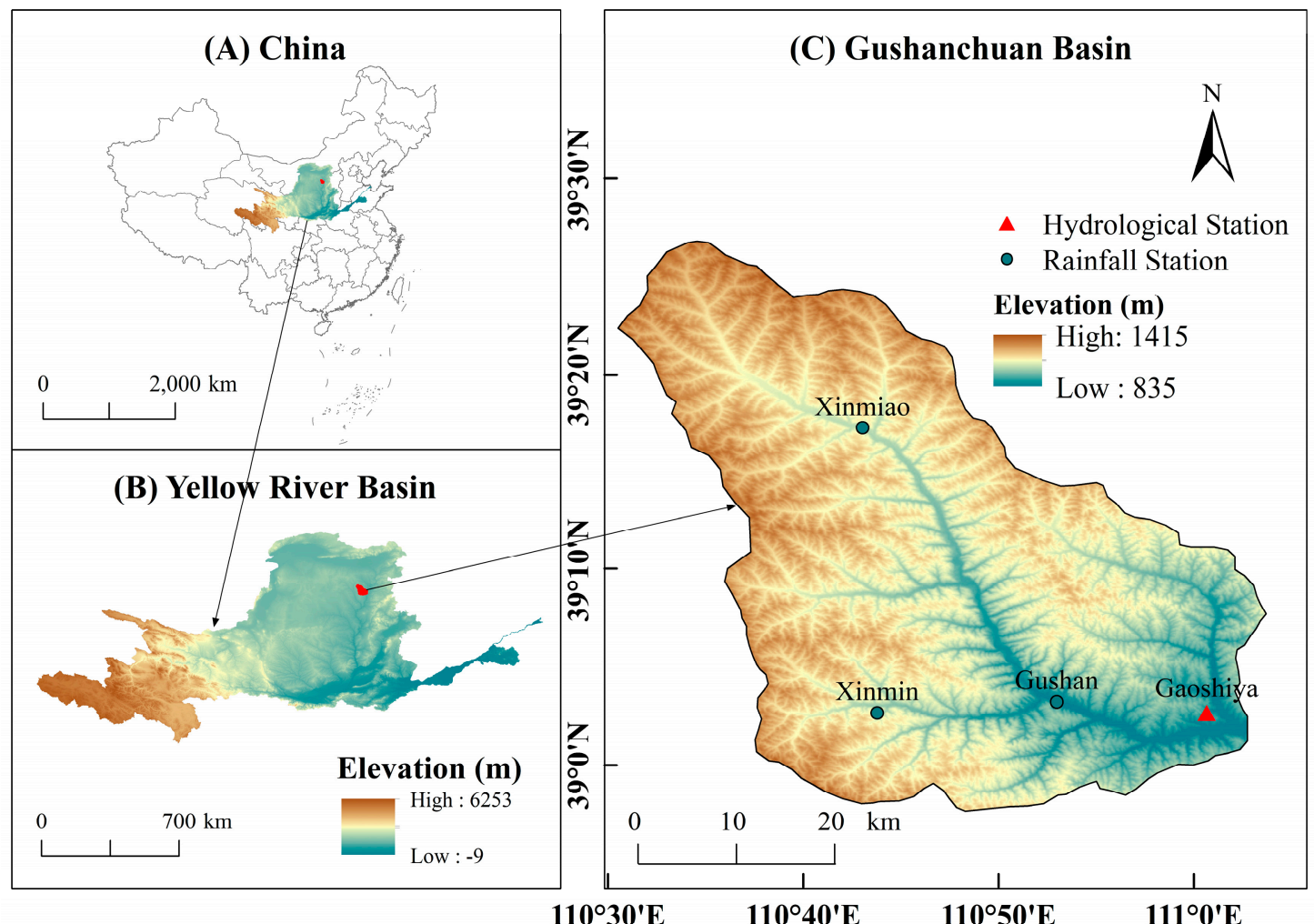

Figure 1. Map of the Gushanchuan basin. (A) Inset map showing the location of the Yellow River Basin in China; (B) Location of the Gushanchuan watershed along the Yellow River basin; (C) The control catchment of Gushanchuan basin and distribution of rainfall-runoff gauge stations.

\subsection{Data Collection}

For the purposed research, we collected annual and hourly data series between 1965 and 2010 of runoff, from Gaoshiya hydrological station in Gushanchuan Basin; hourly rainfall data was obtained from four gauges (Xinmiao, Xinmin, Gushan and Gaoshiya) with a time series of 46 years, from 1965 to 2010. Besides, there is no national level meteorological station in the basin, the evaporation data of Fugu meteorological station in 1965-2010 near the basin is selected, and the evapotranspiration of the basin was calculated by inverse distance weighted interpolation (IDW). All the above data are obtained from the Yellow River Hydrological Yearbook [16]. The spatial resolution of the basin's DEM (Digital Elevation Model) data is $90 \mathrm{~m}$. The land use data comes from Landsat series of remote sensing images, which are acquired by human-computer interactive interpretation based on ENVI (The Environment for Visualizing Images) and ArcGIS, the resolution is $1 \mathrm{~km}$, provided by Geospatial Data Cloud site, Computer Network Information Center, Chinese Academy of Sciences (http://www.gscloud.cn). 


\subsection{Methodology}

\subsubsection{Analysis of Meteo-Hydrological Changes}

In order to identify meteo-hydrological trends, we first apply the widely used Mann-Kendall trend test [17] to the time series of precipitation, runoff and potential evapotranspiration and point out significant changes in Gushanchuan basin. For a time series $X\left(X=x_{1}, x_{2}, \ldots, x_{n}\right)$ which has $\mathrm{n}$ samples, the Mann- Kendall statistics $S$ and UF were given as:

$$
\begin{gathered}
S=\sum_{i=1}^{n-1} \sum_{j=i+1}^{n} \operatorname{sgn}\left(x_{i}-x_{j}\right) \\
U F=\frac{S_{k}-E\left[S_{k}\right]}{\operatorname{Var}\left[S_{k}\right]}(k=1,2, \ldots, n)
\end{gathered}
$$

where $x_{i}$ and $x_{j}$ represent the values in years $i$ and $j, i>j, n$ is the record length of the series, and $\operatorname{sgn}\left(x-x_{j}\right)$ is a characterization of the function. $E\left(S_{K}\right)$ and $\operatorname{Var}\left(S_{K}\right)$ represent the mean and variance of $S_{K}$, respectively.

Then the time series order is reversed (i.e., $x_{n}, x_{n-1}, \ldots, x_{1}$ ) and the above process is repeated to compute statistical variables $U B$. Finally, we draw curves of $U F$ and $U B$, and if the two curves have an intersection point in the confidence level, then it can be considered as a mutation point. Researchers believe that after the hydrological sequence is significantly affected by climate change or human activities, the stability of its distribution sequence will be disturbed or destroyed, showing a certain degree of phase or trend. Therefore, according to the detected runoff mutation point, the research period can be divided into base period and mutation period. The base period watershed is in a natural state, means that the runoff is only affected by climate change. However, in the mutation period, human activities may have a significant impact on the runoff change.

\subsubsection{Estimating the Impact of Climate Variability and Human Activities on Runoff}

For a certain watershed, the total changes $(\Delta R, \mathrm{~mm})$ of runoff is a synthetic production of climate change $\left(\Delta R_{C}, \mathrm{~mm}\right)$ and human activities $\left(\Delta R_{H}, \mathrm{~mm}\right)$, it can be calculated from the difference between the measured runoff before and after the mutation point. Therefore, to quantitatively distinguish the impact of climate change and human activities on runoff, only one factor should be quantified, and the effect of the other factor can be calculated by formula (3). Based on long-term water balance assumptions and the Budyko hypothesis [18], the evapotranspiration $\left(E_{a}\right)$ is a function of the dryness index $\left(\phi=E_{0} / P\right)$. Then the contribution of climate change to runoff can be derived by calculating the elastic coefficient of runoff on precipitation and potential evaporation, which is expressed as:

$$
\begin{gathered}
\Delta R=\Delta R_{C}+\Delta R_{H} \\
\Delta R_{C}=\Delta R_{P}+\Delta R_{E}=\varepsilon_{P} \frac{\bar{R}}{\bar{P}} \Delta P+\varepsilon_{E_{0}} \frac{\bar{R}}{\overline{E_{0}}} \Delta E_{0} \\
\varepsilon_{P}+\varepsilon_{E_{0}}=1 \\
\varepsilon_{P}=1+\frac{\phi F^{\prime}(\phi)}{1-F(\phi)}
\end{gathered}
$$

where $\Delta R_{P}, \Delta R_{E}$ are contributions of rainfall and potential evapotranspiration to runoff, respectively. $\varepsilon_{P}, \varepsilon_{E_{0}}$ are dimensionless parameters which represent elastic coefficients of runoff on precipitation and potential evapotranspiration, respectively; $\bar{P}, \bar{R}$ and $\overline{E_{0}}$ are multi-year average of precipitation (mm), runoff depth $(\mathrm{mm})$ and potential evapotranspiration $(\mathrm{mm})$ of the study basin; $F(\phi)$ and $F^{\prime}(\phi)$ can be calculated by the following Budyko forms [18-21] (Table 1): 
Table 1. Four commonly used forms of $F(\phi)$ and $F^{\prime}(\phi)$ based on the Budyko hypothesis.

\begin{tabular}{ccc}
\hline Forms & $\boldsymbol{F}(\boldsymbol{\phi})$ & $\boldsymbol{F}^{\prime}(\boldsymbol{\phi})$ \\
\hline Budyko & {$\left[\phi \tanh (1 / \phi)\left(1-e^{-\phi}\right)\right]^{0.5}$} & $0.5\left[\phi \tanh (1 / \phi)\left(1-e^{-\phi}\right)\right]^{0.5} \times[(\tanh (1 / \phi)-$ \\
Turc-Pike & $\left(1+\phi^{-2}\right)^{-0.5}$ & $\left.\left.\operatorname{sech}^{2}(1 / \phi) / \phi\right)\left(1-e^{-\phi}\right)+\phi \tanh (1 / \phi) e^{-\phi}\right]$ \\
Fubaopu & $1+\phi-\left(1+\phi^{\alpha}\right)^{1 / \alpha}$ & $1 / \phi^{3}\left[\left(1+(1 / \phi)^{2}\right)^{1.5}\right]$ \\
Zhang & $(1+\omega \phi) /(1+\omega \phi+1 / \phi)$ & $1-\left(1+\phi^{\alpha}\right)^{1 / \alpha-1} \phi^{\alpha-1}$ \\
\hline
\end{tabular}

Note: $\alpha$ and $\omega$ are parameters of each formula. According to optimization method, $\alpha=2.5$ and $\omega=0.9$.

\subsubsection{Runoff Generation Pattern}

Due to the uneven spatial distribution of rainfall and underlying surface conditions, the runoff mechanism is changing during the rainfall process, and nine types of different runoff mechanisms are combined under specific aerated zone structures and rainfall characteristics [22] (Table 2). However, according to the impact factors, it can be divided into two kind of patterns, namely the Excess saturation runoff and the Excess infiltration runoff patterns. Generally, the impact factors of Excess saturation runoff are $P, E, W_{0}$, and the Excess infiltration runoff patterns are $P, E, W_{0}, i$ [23], which is expressed as:

$$
\begin{gathered}
R=f_{\text {storage }}\left(P, E, W_{0}\right) \\
R=f_{\text {excess }}\left(P, E, W_{0}, i\right)
\end{gathered}
$$

where $R$ is runoff depth generated by rainfall ( $\mathrm{mm}) ; P$ is the total amount of precipitation $(\mathrm{mm}) ; E$ is watershed evapotranspiration $(\mathrm{mm}) ; W_{0}$ is initial water storage capacity $(\mathrm{mm}) ; i$ is rainfall intensity $(\mathrm{mm} / \mathrm{h})$.

Table 2. Combination of basin runoff generation mechanism.

\begin{tabular}{cccccc}
\hline Type & $\begin{array}{c}\text { Composition } \\
\text { of Runoff }\end{array}$ & Impact Factors & Type & $\begin{array}{c}\text { Composition } \\
\text { of Runoff }\end{array}$ & Impact Factors \\
\hline 1 & $R=R_{s}$ & $P, E, W_{0}, i$ & 6 & $R=R_{\text {sat }}+R_{\text {int }}$ & $P, E, W_{0}, i$ \\
2 & $R=R_{s}+R_{g}$ & $P, E, W_{0}$ & 7 & $R=R_{\text {sat }}+R_{\text {int }}+R_{g}$ & $P, E, W_{0}$ \\
3 & $R=R_{g}$ & $P, E, W_{0}$ & 8 & $R=R_{\text {int }}$ & $P, E, W_{0}, i$ \\
4 & $R=R_{s}+R_{\text {int }}$ & $P, E, W_{0}, i$ & 9 & $R=R_{\text {int }}+R_{g}$ & $P, E, W_{0}$ \\
5 & $R=R_{s}+R_{\text {int }}+R_{g}$ & $P, E, W_{0}$ & & & \\
\hline
\end{tabular}

In addition, owing to the complexity of the spatial and temporal distribution of rainfall, the above two runoff patterns are intertwined which leads to the so-called Mixed runoff. This usually occurs in semi-arid and semi-humid areas. Therefore, the runoff pattern is the embodiment of different runoff mechanism combinations of each unit in the watershed. However, for a specific watershed, its runoff process is not static and difficult to describe quantitatively with simple indicators. Table 3 shows the integrated analysis of this study along with the runoff generation pattern to deduce the runoff process qualitatively, quantitatively, and comprehensively [24], on the basis of flood generation mechanism in the Gushanchuan Basin. 
Table 3. Comprehensive analysis table of runoff generation patterns.

\begin{tabular}{ccc}
\hline Objects & Excess Saturation Runoff & Excess Infiltration Runoff \\
\hline Average annual rainfall & $P>1000 \mathrm{~mm}$ & $P<400 \mathrm{~mm}$ \\
Runoff coefficient & $>0.4$ & $<0.2$ \\
Symmetry of Flow Process Line & High & Low \\
Impacts of rainfall intensity & Low & High \\
Influencing factors of flow & $P_{a} P$ & $P_{a}, i$ \\
Surface soil structure & Loose & Compact \\
Water shortage capacity & Small & Big \\
Proportion of $R_{g}$ & High & Low \\
Relativity & Related to $P$ & Related to $i$ \\
\hline
\end{tabular}

\subsubsection{Antecedent Precipitation Index}

Antecedent precipitation index $\left(P_{a}\right)$ reveal the amount of rainfall that was retained in the soil during the previous rainfall [25]. In this study, the recursive formula was used to estimate the amount of $P_{a}$ in the early stage of the flood, computed as:

$$
P_{a, t}=k P_{t-1}+k^{2} P_{t-2}+\cdots+k^{n}\left(P_{a, t-n}+P_{t-n}\right)
$$

And from this, the formula for calculating the amount of rainfall in the early stage is derived:

$$
P_{a, t+1}=k\left(P_{a, t}+P_{t}\right)
$$

where $P_{a, t}$ is the antecedent precipitation index $(\mathrm{mm})$ on day $\mathrm{t} ; n$ is the number of previous rain days affecting the runoff, usually takes about 15 days, $P_{t}$ is the $t$-day rainfall $(\mathrm{mm}) ; P_{t-1}, P_{t-2} \ldots$ is the rainfall $(\mathrm{mm})$ on the 1 day before $t$ day, 2 days before. The daily decrease coefficient of soil water content $k$ is calculated by the following formula:

$$
k=1-\frac{E_{m}}{W_{m}}
$$

where: $E_{m}$ is the watershed evapotranspiration capacity $(\mathrm{mm}) ; W_{m}$ is the water storage capacity $(\mathrm{mm})$ of the basin

\subsubsection{Watershed Water Storage Capacity}

The watershed water storage capacity $\left(W_{m}\right)$ is derived from multiple flood events [26], which selects the rainfall floods that can make the water content of the basin saturated and generate a large flood process. Then let $W_{m, 0}=I_{m}$, where the loss $I_{m}=P-R$. The calculation process of $W_{m}$ can be estimated as:

$$
\begin{gathered}
K_{j}=1-\frac{E_{m}}{W_{m, j}} \\
W_{0, j}=\sum_{0}^{n} P_{i} \times k_{j}^{i} \\
W_{m, j}=W_{m, j-1}+W_{0, j-1}
\end{gathered}
$$

where $K_{j}$ is daily decrease coefficient of soil water content under different iterations; $P_{i}$ is the rainfall for the $i$ day before the flood (mm); $i$ is the power; $j$ is the number of iterations; $W_{m, 0}$ is the assumed value for the first iteration $(\mathrm{mm})$. After several iterations, $W_{m}$ tends to a stable value, which is the water storage capacity of the basin. 


\section{Results and Discussion}

\subsection{Analysis of Meteo-Hydrologic Changes}

Over the past 50 years, the annual runoff in the Gushanchuan Basin has shown a downward trend. From 1965 to 1980, the annual runoff fluctuated greatly, and after 1980, the runoff decreased

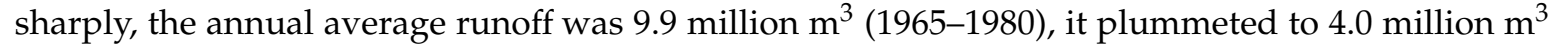
(1981-2010), the latter being merely $40.3 \%$ of the former (Figure 2A). The Mann-Kendall trend test was used to analyze the precipitation, runoff, and potential evapotranspiration in the Gushanchuan Basin. The results show that the statistical $Z_{C}$ values of the above meteo-hydrological factors are $0.08,-0.29$, and -4.53 , respectively. However, only the absolute value of runoff statistical value $Z_{C}>1.96$, indicates that the runoff change in the study area has reached a significant level. According to the Figure 2B, two curves intersected in 1997, and the intersection point was laid in two 95\% confidence lines, showing that the annual runoff was abruptly changed around 1997, considering the vegetation restoration on the Loess Plateau since 1997, the vegetation adaptation to flooding events in terms of physiological, morphological, and biomechanical properties, may lead to the decrease of runoff [27]. Compared with the pre-mutation period, the annual runoff and precipitation in the catchment during the post-period decreased by $2.5 \%$ and $77 \%$, but only the annual runoff series shows a significant downward trend within the confidence level of 0.5 (Table 4). The annual potential evapotranspiration changes are too small to attract attention. Hence, significant changes in runoff are not just caused by climate change, and human activities may have played an important role during this period.
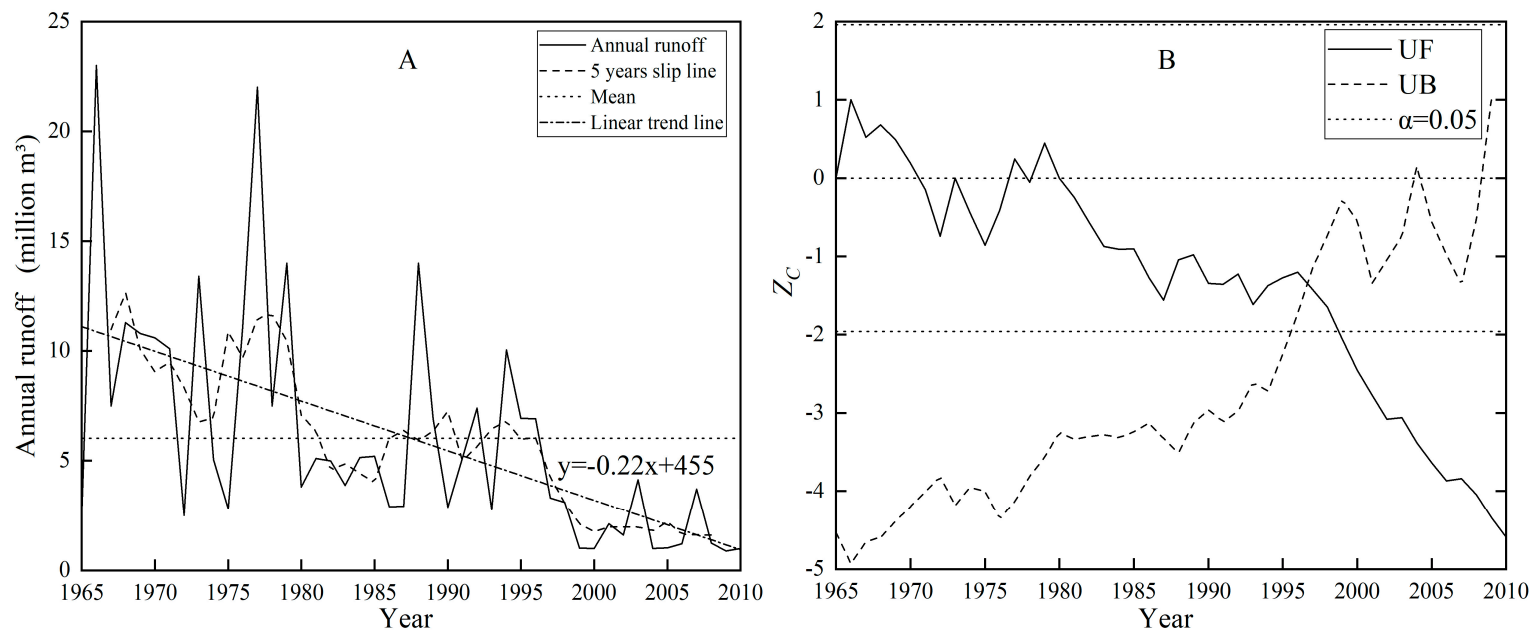

Figure 2. Trend analysis (A) and mutation point of annual runoff (B) in Gushanchuan basin.

Table 4. Variation of meteo-hydrological factors around the mutation point of Gushanchuan basin.

\begin{tabular}{cccccc}
\hline \multirow{2}{*}{ Variables } & \multirow{2}{*}{$Z_{C}$} & \multirow{2}{*}{ Significant } & \multicolumn{2}{c}{ Mean Value (mm) } & \multirow{2}{*}{ Change (\%) } \\
\cline { 4 - 5 } & & & $\mathbf{1 9 6 5 - 1 9 9 7}$ & $\mathbf{1 9 9 8 - 2 0 1 0}$ & \\
\hline $\mathrm{P}$ & -0.08 & $n s$ & 427.1 & 402.4 & -2.5 \\
$\mathrm{E}_{0}$ & -0.29 & $n s$ & 2426.3 & 2410.7 & -0.0 \\
$\mathrm{R}$ & -4.53 & $* *$ & 60.5 & 13.9 & -77.0 \\
\hline
\end{tabular}

Note: $n s$ indicates significance level exceeds $0.05 ; * *$ indicates significance levels of 0.0 .5 .

According to the principle of water balance, the change of annual runoff for many years is the product of the combined effect of precipitation and potential evapotranspiration. In order to deeply understand the reasons for the decrease of runoff in Gushanchuan basin, the spatial distribution of changes in the average annual precipitation and potential evapotranspiration are shown in Figure 3. From the base period to the mutation period, the multi-year average precipitation of each rainfall 
station has decreased to varying degrees, especially in the northwest and southwest regions of the basin. The largest decrease in rainfall occurs at Xinmiao Station, which is $-48--44 \mathrm{~mm}$ (Figure 3A). The decrease in precipitation at each rainfall station is the direct cause of the runoff reduction in Gushanchuan basin. The spatial patterns of changes in potential evapotranspiration were generally consistent, which characterized by the more decrease in the upstream region than that in the downstream region (Figure 3B).

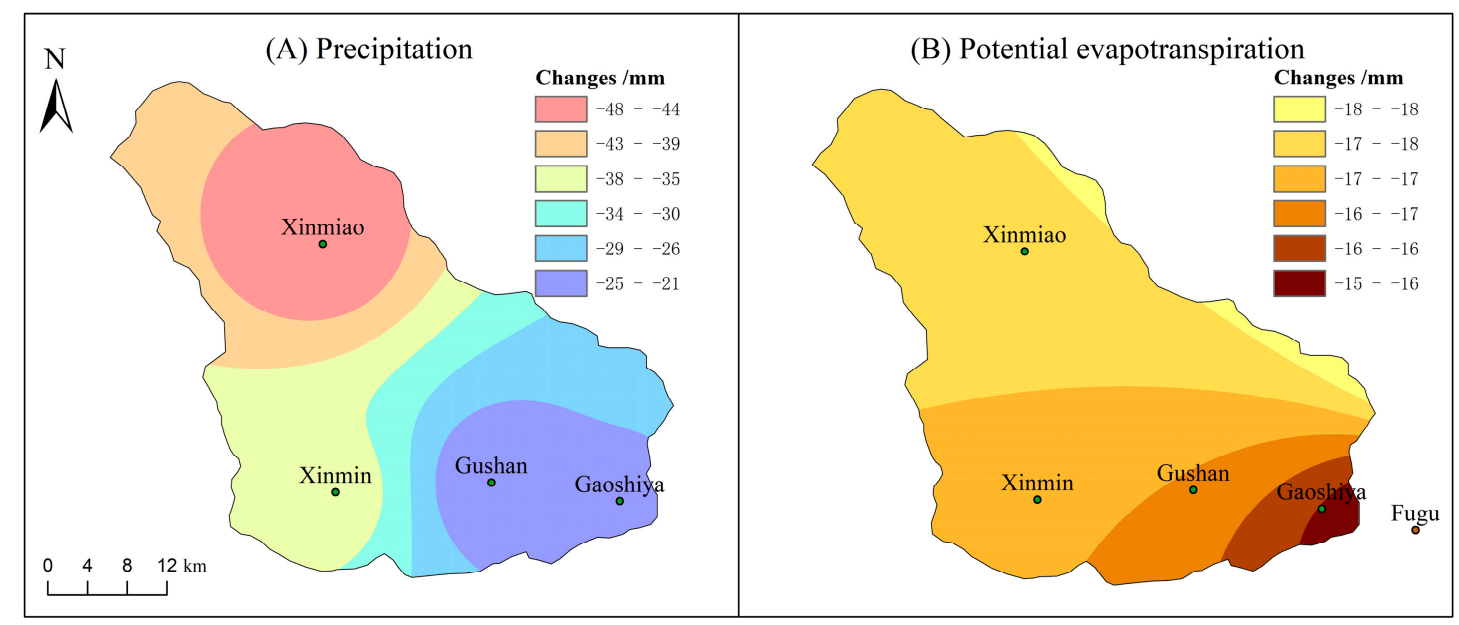

Figure 3. Changes of precipitation (A) and potential evapotranspiration (B) in Gushanchuan basin.

The impact of climate change and human activities on runoff change based on Budyko hypothesis is represented in Table 5. The results manifest that the elasticity coefficients of runoff to precipitation estimated by using four functions based on the Budyko hypothesis are very close, with an average value of 2.5. The contribution rate of climate change to runoff change is between $12.9 \%$ and $15.1 \%$, and the contribution rate of human activities to runoff change is between $84.9 \%$ and $87.1 \%$, and the average values are $13.9 \%$ and $86.1 \%$, respectively. This result is similar to that of Zhan [28], which investigated the relative contributions of human activity and climate change to the hydrological response of the Weihe River Basin, the largest tributary of the Yellow River. However, all the methods adopted by them belong to the category of statistical methods and lack of physical mechanism. Wang [29] used data from 1958-2008 to explore the factors influencing the reduction of runoff in Huangfuchuan Basin, based on the methods of accumulative anomaly analysis. The results show that the contribution rates of human activities to the runoff change in Huangfuchuan Basin are $63.57 \%$ and $83.19 \%$, during the period of 1980-1997 and 1998-2008, respectively. Overall, the analysis seems to suggest that the human activities play a critical role in the reduction of runoff in the Yellow River basin.

Table 5. Separating the effects of climate change and human activities by climate elasticity method.

\begin{tabular}{cccccc}
\hline Variables & Budyko & Turc-Pike & Fubaopu & Zhang & Average \\
\hline$\varepsilon_{P}$ & 2.6 & 2.7 & 2.4 & 2.3 & 2.5 \\
$\Delta R_{C}(\mathrm{~mm})$ & -6.8 & -7.0 & -6.3 & -6.0 & -6.5 \\
$\Delta R_{H}(\mathrm{~mm})$ & -39.8 & -39.6 & -40.3 & -40.6 & -40.1 \\
$\Delta R_{C}(\%)$ & 14.6 & 15.1 & 13.5 & 12.9 & 13.9 \\
$\Delta R_{H}(\%)$ & 85.4 & 84.9 & 86.5 & 87.1 & 86.1 \\
\hline
\end{tabular}

\subsection{Characteristics of LUCC (Land Use and Cover Changes)}

In the past 50 years, many soil and water conservation measures such as afforestation, check dams and terracing have been implemented. As of 2010, a total of 49 small and medium check dams were built, with a dam area of $8.9 \mathrm{~km}^{2}$, accounting for $0.70 \%$. The scale of terracing has gradually increased, with a terracing ratio of $2.97 \%$, and the number of reservoirs has also increased [30]. All these human 
activities greatly altered the land use and land cover, and further affected the land surface hydrological processes [31,32]. Then we analyzed the relationship of land use conversion based on three periods of remote sensing data from 1976, 1996, and 2006. Showing that the proportion of grassland area in the Gushanchuan Basin is the largest (60.89-62.92\%), followed by farmland (30.59-32.52\%), and the urban construction land area is the smallest $(0.35-0.55 \%)$. Between 1976 and 2006, the area of farmland decreased year by year, and the area of forest, grassland and urban construction land increased in different extents, and the water area remained basically stable. In addition, farmland has the greatest change in area among all land use types. The total cultivated area of $24.52 \mathrm{~km}^{2}$ has been converted to other land use types. The main conversion form is conversion of farmland into forest land, and grassland into forest land. The forest area is increased by $18.22 \mathrm{~km}^{2}$, the grass area increased by $5.39 \mathrm{~km}^{2}$, demonstrating that the effect of the policy "reverting farmland to forests, returning farmland to grassland" was significant (Figure 4, Table 6).
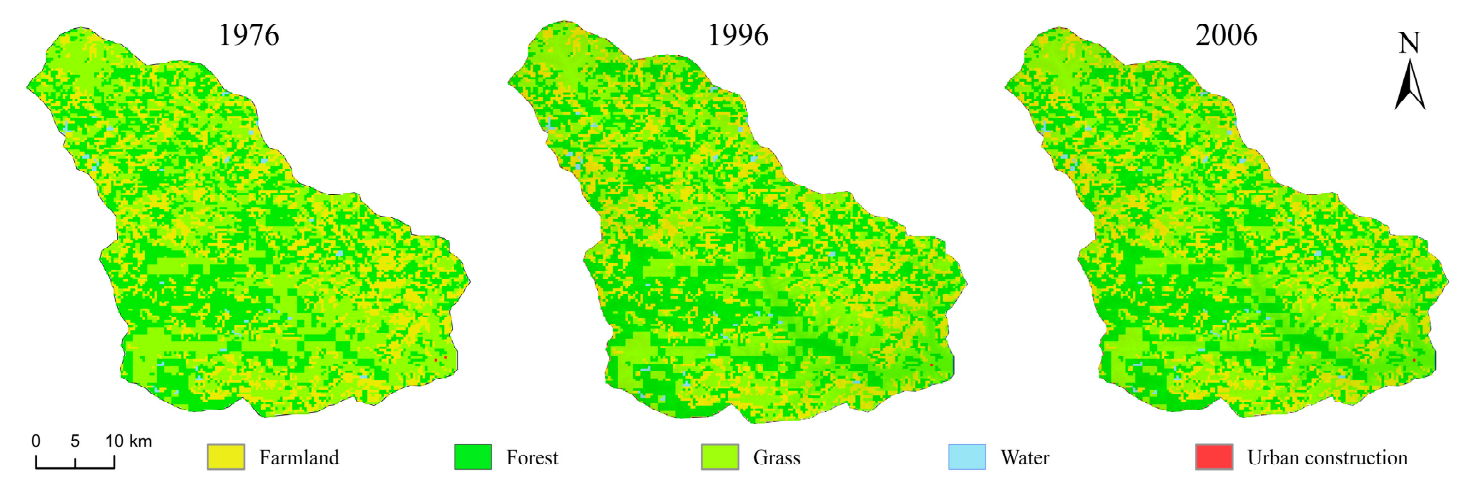

Figure 4. Land use changes of Gushanchuan basin.

Table 6. Land use classification statistics of Gushanchuan basin.

\begin{tabular}{|c|c|c|c|c|c|c|}
\hline $\begin{array}{ll}\text { Year } & \text { Type } \\
\end{array}$ & $\begin{array}{l}\text { Farmland } \\
\left(\mathrm{km}^{2}\right)\end{array}$ & $\begin{array}{r}\text { Forest } \\
\left(\mathrm{km}^{2}\right)\end{array}$ & $\begin{array}{l}\text { Grass } \\
\left(\mathrm{km}^{2}\right)\end{array}$ & $\begin{array}{l}\text { Water } \\
\left(\mathrm{km}^{2}\right)\end{array}$ & $\begin{array}{c}\text { Urban Construction } \\
\left(\mathbf{k m}^{2}\right)\end{array}$ & $\begin{array}{r}\text { Sum } \\
\left(\mathrm{km}^{2}\right)\end{array}$ \\
\hline 1976 & 413.68 & 65.47 & 774.55 & 12.28 & 6.02 & 1272 \\
\hline 1996 & 405.94 & 48.41 & 800.32 & 12.82 & 4.51 & 1272 \\
\hline 2006 & 389.16 & 83.69 & 779.94 & 12.16 & 7.05 & 1272 \\
\hline Average & 402.93 & 65.85 & 784.94 & 12.42 & 5.86 & 1272 \\
\hline Proportion (\%) & 31.68 & 5.18 & 61.71 & 0.97 & 0.46 & 100 \\
\hline
\end{tabular}

\subsection{Correlation of Rainfall-Runoff}

Based on the mutation point of the Gushanchuan Basin, the time sequence data was divided into two stages for the research, and in accordance with the principle that the flood peak flow is greater than $100 \mathrm{~m}^{3} / \mathrm{s}$, the first stage (1965-1997) collected 111 flood events, and the second stage (1998-2010) collected 24 times, with a total of 135 rainfall and flood data. Then we analyzed the rainfall-runoff characteristics of each flood event. Due to the influence of climate and land use changes, the rainfall-runoff relationship is different at each stage. The rainfall-runoff correlation coefficients in two stages are 0.48 and 0.65 , respectively. In comparison, the rainfall of flood events in has decreased significantly associated with the second stage (Figure 5A). The correlation between rainfall intensity and runoff shows a slight downward trend, namely 0.56 and 0.51 . For the flood events of the same magnitude of rainfall intensity in the two stages, the runoff is greater in the second stage (Figure 5B). Different from the humid area, the correlation coefficient of rainfall and runoff in this basin is relatively low, which can be analyzed from two aspects: (1) The effect of land cover changes. The grassland in Gushanchuan watershed can alleviate the impact of raindrops on the surface soil, increase the roughness of the surface soil, and reduce the impact of rainfall on runoff generation. With the increase of rainfall intensity, the rainfall that can penetrate the grass layer increases, namely, the infiltration capacity of the surface soil increases, so the runoff yield increases apparently. (2) The influence of 
antecedent precipitation index $\left(P_{a}\right)$. The amount of $P_{a}$ in the soil not only affects how much water the surface soil can store at the beginning of rainfall, but also affects the infiltration rate of soil water. Therefore, the $P_{a}$ is also a very important factor affecting runoff. The lower the soil water content, the later the runoff generation begins [33].
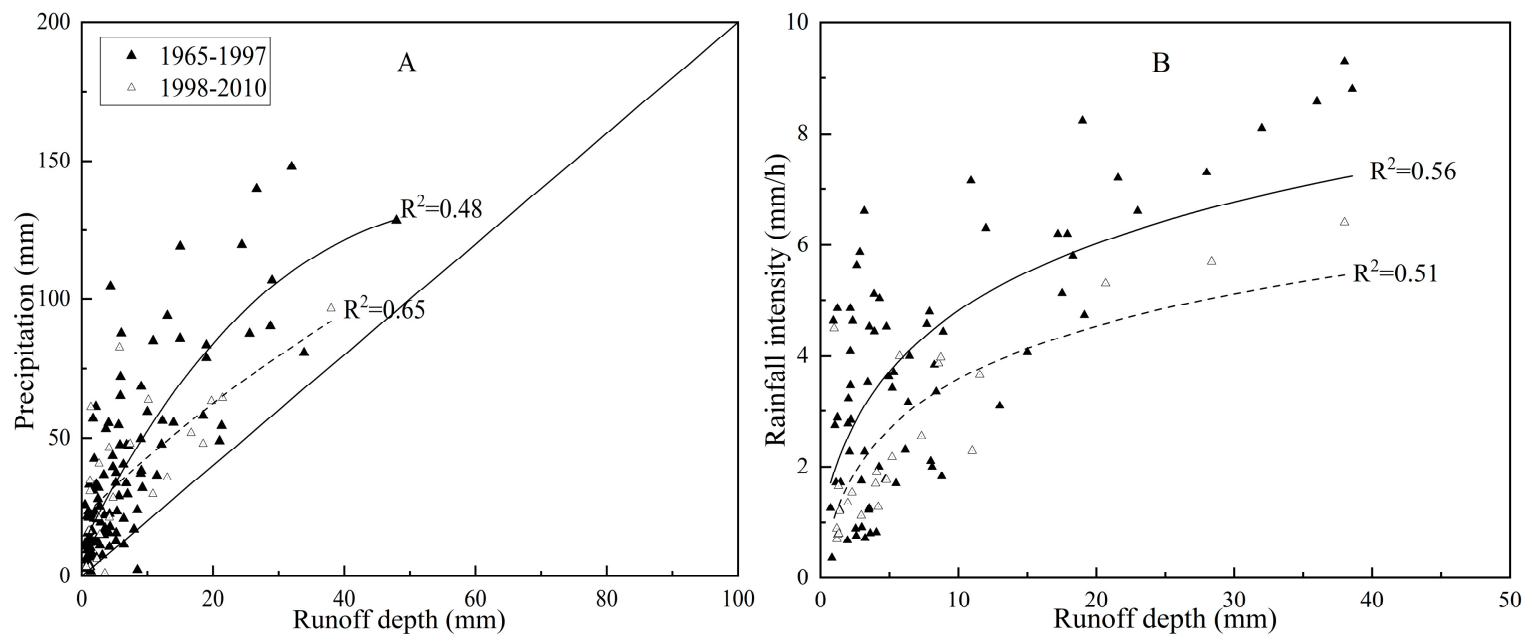

Figure 5. Correlation of runoff depth against precipitation (A) and rainfall intensity (B) in Gushanchuan Basin.

The rainfall duration of the Gushanchuan Basin has increased, and most of the rainfall lasted between $20-40 \mathrm{~h}$. The mean rainfall at each stage were 47.9 and $38.0 \mathrm{~mm}$. Based on the criteria of meteorological classification, the flood events are divided into four levels: light rain $(P<10 \mathrm{~mm})$, moderate rain $(10-25 \mathrm{~mm})$, heavy rain $(25-50 \mathrm{~mm})$ and rainstorm $(P>50 \mathrm{~mm})$. Among the whole flood events, there were 21 light rains, 45 moderate rains, 39 heavy rains and 30 rainstorms. Therefore, the Gushanchuan Basin mainly suffered from moderate rains and heavy rains. The flood duration showed a slightly increase trend, as well as the peak flow showed a significant decrease over the years (Table 7). Under the influence of land use and cover changes, a similar phenomenon also appeared in the Chabagou basin, a tributary of the Yellow River [34].

Table 7. Characteristics of flood events in different stages of Gushanchuan basin.

\begin{tabular}{cccc}
\hline Characteristics & $\mathbf{1 9 6 5 - 1 9 9 7}$ & $\mathbf{1 9 9 8 - 2 0 1 0}$ & Change (\%) \\
\hline Mean rainfall duration $(\mathrm{h})$ & 12.3 & 17.3 & 40.7 \\
Mean rainfall $(\mathrm{mm})$ & 47.9 & 38.0 & -20.7 \\
Mean flood duration $(\mathrm{h})$ & 47.6 & 53.8 & 13.0 \\
Mean peak flow $\left(\mathrm{m}^{3} / \mathrm{s}\right)$ & 1480.6 & 314.7 & -78.7 \\
\hline
\end{tabular}

\subsection{Diagnostic Analysis of the Runoff Generation Process}

We collected the characteristics of three typical floods in the Gushanchuan Basin. In the 19680821 flood (Figure 6A), the total rainfall was $31.36 \mathrm{~mm}$, the rainfall lasted for $12 \mathrm{~h}$, the average rainfall intensity was $2.6 \mathrm{~mm} / \mathrm{h}$, and the maximum rainfall intensity was $8.7 \mathrm{~mm} / \mathrm{h}$. The total rainfall during this rainfall process was small and short in duration, but the short-term rainfall intensity was heavy. According to the law of runoff generation, the main components of the runoff of this flood were surface runoff and interflow. The antecedent precipitation index $\left(P_{a}\right)$ was only $2.3 \mathrm{~mm}$, with dry and compact soil, combined with the Table 3, indicated that the flood is mainly dominated by Excess infiltration runoff. During the 15 days before the 19950728 flood (Figure 6B), light rain continued to occur and the surface soil layer was relatively humid, the $P_{a}$ was calculated to be $23.2 \mathrm{~mm}$ in early stage. The rainfall intensity of this flood was not great, but it was more evenly distributed in space, and the runoff 
coefficient was 0.42 . It can be considered that the surface layer of the basin is full, and the type of runoff generation mechanism was $R_{s}+R_{i n t}+R_{g}$, namely, Excess saturation runoff pattern; The 19940802 flood (Figure 6C) was a multi-peak flood. There was almost no rain in the first half month of the basin, which confirms that the runoff generation pattern in the early phase was mainly Excess infiltration runoff. With continuous rainfall leading to an increase in soil water content, the runoff generation type has changed from a single surface runoff mechanism $\left(R_{S}\right)$ to $R_{S}+R_{i n t}+R_{g}$, and it is comprehensively judged that this flood is a Mixed runoff pattern. We can see that the rainfall and $P_{a}$ in the 19680821 flood was small, while the rainfall and $P_{a}$ in the 19950728 flood were both large. Although the rainfall in the Mixed runoff flood was larger, reaching $72.53 \mathrm{~mm}$, the $P_{a}$ in the early stage was extremely small, which leads to the Excess infiltration runoff pattern in the early stage of the basin. Hence, the antecedent precipitation index in the early stage is also a very important factor for basin runoff generation process.
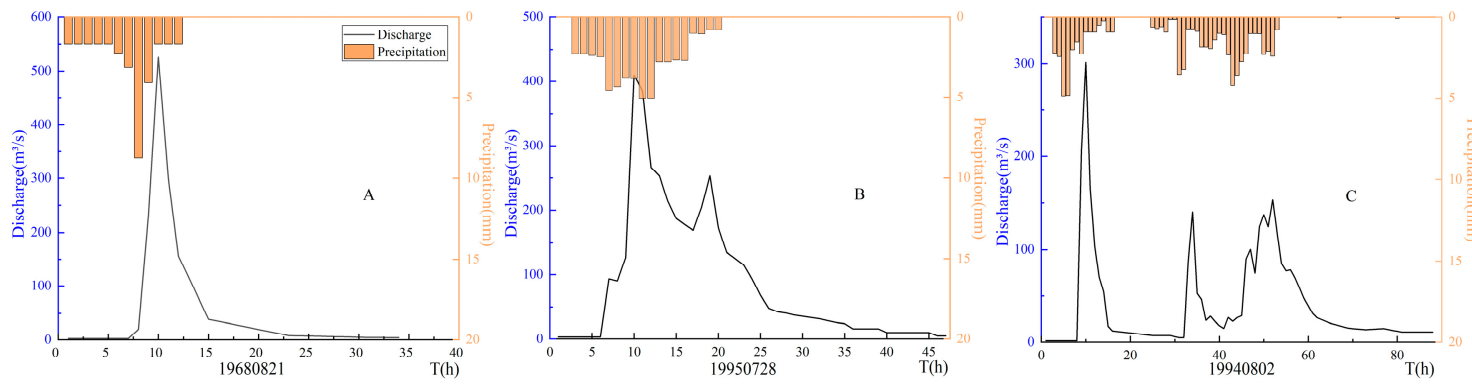

Figure 6. 19680821 (A), 19950728 (B) and 19940802 (C) flood process line of Gushanchuan Basin.

From 1965 to 2010, the Gushanchuan Basin was dominated by Excess infiltration runoff, accounting for $64.44 \%$ of the flood events, and the Mixed runoff accounted for $32.60 \%$, only 4 Excess saturation runoffs happened during this period. In these two stages, the floods with Excess infiltration runoff accounted for $68.46 \%$ and $45.83 \%$ of the total floods, respectively, as well as the proportion of Excess infiltration runoff decreased significantly. The proportion of Mixed runoff increased apparently by the stage, namely $30.63 \%$ and $41.67 \%$. Nevertheless, the various stages are still dominated by Excess infiltration runoff, but the proportion of its occurrence is decreasing, while the proportion of another two kinds of runoff generation patterns is increasing (Table 8).

Table 8. Statistics of runoff generation patterns in different stages.

\begin{tabular}{|c|c|c|c|c|}
\hline $\begin{array}{ll}\text { Year } & \text { Pattern } \\
\end{array}$ & $\begin{array}{c}\text { Excess Infiltration } \\
\text { Runoff }\end{array}$ & $\begin{array}{c}\text { Excess Saturation } \\
\text { Runoff }\end{array}$ & Mixed Runoff & Sum \\
\hline $\begin{array}{l}\text { First stage } \\
1965-1997\end{array}$ & $76(68.46 \%)$ & $1(0.10 \%)$ & $34(30.63 \%)$ & $111(100 \%)$ \\
\hline $\begin{array}{c}\text { Second stage } \\
1998-2010\end{array}$ & $11(45.83 \%)$ & $3(12.50 \%)$ & $10(41.67 \%)$ & $24(100 \%)$ \\
\hline Sum & 87 (64.44\%) & $4(2.96 \%)$ & $44(32.60 \%)$ & $135(100 \%)$ \\
\hline
\end{tabular}

The area of forest in the Gushanchuan Basin increases rapidly, and vegetation can increase rainfall infiltration by improving soil organic matter and porosity. Therefore, land use cover change is an important reason for the change of rainfall runoff [35], which affects the process of runoff generation by affecting the outflow capacity of groundwater, infiltration capacity and water storage capacity [36]. The annual minimum daily flow and the minimum daily flow in flood season can reflect the outflow capacity of groundwater, which has increased gradually in the Gushanchuan Basin, especially in 1998-2010, the groundwater outflow capacity increased significantly, resulting in increased confluence time and reduced peak flow. The area of forest increased by $49.61 \%$, the discharge capacity of groundwater increased by $44.04 \%$, the average precipitation before generate flow increased by $90.72 \%$, and the confluence time increased by $50.42 \%$ (Table 9 ). 
Table 9. Statistics on the convergence characteristics of Gushanchuan Basin.

\begin{tabular}{cccc}
\hline Items & $\mathbf{1 9 6 5 - 1 9 9 7}$ & $\mathbf{1 9 9 8 - 2 0 1 0}$ & Change (\%) \\
\hline Forest areas $\left(\mathrm{km}^{2}\right)$ & 55.94 & 83.69 & 49.61 \\
Annual minimum flow $\left(\mathrm{m}^{3} / \mathrm{s}\right)$ & 1.01 & 1.40 & 32.67 \\
Minimum daily flow in flood season $\left(\mathrm{m}^{3} / \mathrm{s}\right)$ & 1.93 & 2.78 & 44.04 \\
Mean precipitation before generate flow $(\mathrm{mm})$ & 9.7 & 18.5 & 90.72 \\
Duration of flood recession $(\mathrm{h})$ & 14.32 & 21.54 & 50.42 \\
Catchment water storage capacity $(\mathrm{mm})$ & 73.17 & 95.38 & 30.35 \\
\hline
\end{tabular}

Generally, with the increase of rainfall amount and intensity, runoff coefficient will gradually increase. The process of infiltration is also an important reason for the change of the runoff generation mechanism [37]. The stable infiltration rate of forest and grassland is greater than that of farmland, and the vegetation affects soil structure, chemical composition and bulk density. Hence, changes in vegetation play an important role in the redistribution of rainfall. Normally, deep root vegetation can alter soil properties to accommodate its water requirements, which may change the soil channels, increase soil porosity and permeability $[38,39]$. Studies have shown that the water storage capacity of forest land is higher than that of other land-use types, and the increase of water storage capacity will lead to an increase in underground runoff, runoff coefficient and confluence time, a decrease in peak flow [40]. The forest area in Gushanchuan Basin increased by $49.61 \%$, the catchment water storage capacity increased by $30.35 \%$ (Table 9), and other studies have reached similar conclusions [41].

\section{Conclusions}

In this research, we selected Gushanchuan basin as the research object, to detect annual runoff trend and analyze the changes of the runoff generation process based on the flood events data from 1965 to 2010. Showing that the Gushanchuan Basin has experienced runoff decline as large as $77 \%$ in the last century, which is mainly caused by human activities. The runoff generation pattern of the basin is dominated by Excess infiltration runoff, but it has also changed to some extent, which is manifested in the increase of runoff components, the proportion of Excess infiltration runoff decreased, and the proportion of Excess saturation runoff and Mixed runoff increased stage by stage. The variety of land use conditions by human activities is the main factor affecting the change of the runoff generation process of the basin. Land use and cover change, as important factors that cause runoff change, especially in the flood season, cannot be ignored. In the present paper, we only take the Gushanchuan Basin as an example. How much of the land use type of the Loess Plateau has changed? Whether its runoff generation process has co-varied? It can also be expanded in the later period in order to further understand the law of the runoff generation of the Yellow River Basin. In addition, this study considers the effects of various human activities as a whole, but its comprehensive effects are extremely sophisticated. We also expect to further refine the research on the response of runoff changes to different human activities in future research.

Author Contributions: All authors have read and agree to the published version of the manuscript. Conceptualization, C.H. and S.J.; methodology, L.Z.; software, Q.W.; validation, C.H., Q.W. and L.Z.; formal analysis, L.Z.; investigation, L.Z.; resources, C.H.; data curation, L.Z.; writing—original draft preparation, L.Z.; writing-review and editing, C.H.; supervision, S.-e-h.S.; project administration, C.H.; funding acquisition, C.H.

Funding: This research was funded by [National Key Research Priorities Program of China], grant number [2016YFC04024023], [National Natural Science Foundation of China], grant number [51979250], [Key projects of National Natural Science Foundation of China], grant number [51739009], [National Natural Science Foundation of China] grant number [31700370].

Acknowledgments: We would like to thank the potential reviewer very much for their valuable comments and suggestions. We also thank my other colleagues' valuable comments and suggestions that have helped improve the manuscript.

Conflicts of Interest: The authors declare no conflict of interest. 


\section{References}

1. Zhao, G.; Mu, X.; Wen, Z.; Wang, F.; Gao, P. Soil erosion, conservation, and eco-environment changes in the loess plateau of china. J. Land Degrad. Dev. 2013, 24, 499-510. [CrossRef]

2. Zhang, B.; He, C.; Burnham, M.; Zhang, L. Evaluating the coupling effects of climate aridity and vegetation restoration on soil erosion over the loess plateau in china. J. Sci. Total Environ. 2016, 539, 436-449. [CrossRef] [PubMed]

3. Wei, J.; Zhou, J.; Tian, J.; He, X.; Tang, K. Decoupling soil erosion and human activities on the Chinese loess plateau in the 20th century. J. Catena 2006, 68, 10-15. [CrossRef]

4. Feng, X.; Fu, B.; Piao, S.; Wang, S.; Ciais, P.; Zeng, Z. Revegetation in china's loess plateau is approaching sustainable water resource limits. J. Nat. Clim. Chang. 2016, 6, 1019. [CrossRef]

5. Zhou, J.; Fu, B.; Gao, G.; Lü, Y.; Liu, Y.; Lü, N.; Wang, S. Effects of precipitation and restoration vegetation on soil erosion in a semi-arid environment in the loess plateau, china. J. Catena 2016, 137, 1-11. [CrossRef]

6. Mu, X.; Zhang, X.; Shao, H.; Gao, P.; Wang, F.; Jiao, J.; Zhu, J. Dynamic changes of sediment discharge and the influencing factors in the yellow river, china, for the recent 90 years. J. Clean-Soil Air Water 2012, 40, 303-309. [CrossRef]

7. Wang, S.; Fu, B.J.; Piao, S.; Lü, Y.; Ciais, P.; Feng, X.; Wang, Y. Reduced sediment transport in the yellow river due to anthropogenic changes. J. Nat. Geosci. 2015, 9, 38. [CrossRef]

8. Feng, X.; Sun, G.; Fu, B.; Su, C.; Liu, Y.; Lamparski, H. Regional effects of vegetation restoration on water yield across the loess plateau, china. J. Hydrol. Earth Syst. Sci. Discuss. 2012, 16, 2617-2628. [CrossRef]

9. Pasquino, V.; Gualtieri, P.; Doria, G. On evaluating flow resistance of rigid vegetation using classic hydraulic roughness at high submergence levels: An experimental work. In Hydrodynamic and Mass Transport at Freshwater Aquatic Interfaces; GeoPlanet: Earth and Planetary Sciences; Rowiński, P., Marion, A., Eds.; Springer: Cham, Switzerland, 2016; pp. 269-277.

10. Aberle, J.; Järvelä, J. Flow resistance of emergent rigid and flexible floodplain vegetation. J. Hydraul. Res. 2013, 51, 33-45. [CrossRef]

11. Shi, C.; Zhou, Y.; Fan, X.; Shao, W. A study on the annual runoff change and its relationship with water and soil conservation practices and climate change in the middle yellow river basin. J. Catena 2013, 100, 31-41. [CrossRef]

12. Horton, R. The role of infiltration in the hydrologic cycle. J. Eos Trans. Am. Geophys. Union 1933, 14, 446. [CrossRef]

13. Hewlett, J.; Hibbert, A. Moisture and energy conditions within a sloping soil mass during drainage. J. Geophys. Res. 1963, 68, 1081-1087. [CrossRef]

14. Dunne, T.; Black, R. Partial area contributions to storm runoff in a small new England watershed. J. Water Resour. Res. 1970, 6, 1296-1311. [CrossRef]

15. Liu, D.; Tian, F.; Hu, H.; Hu, H. The role of run-on for overland flow and the characteristics of runoff generation in the loess plateau, china. Hydrol. Sci. J. 2012, 57, 1107-1117. [CrossRef]

16. Hydrological Yearbook of People's Republic of China-Hydrological Data of Yellow River Basin; Hydrological Bureau of the Ministry of Water Resources of the People's Republic of China: Zhengzhou, China, 2013; pp. 1965-2010.

17. Mann, H.B. Nonparametric tests against trend. J. Econom. J. Econom. Soc. 1945, 13, 245-259. [CrossRef]

18. Budyko, M.I.; David, H. Climate and life; Academic Press: New York, NY, USA, 1974; Volume 508, pp. 23-24.

19. Pike, J. The estimation of annual run-off from meteorological data in a tropical climate. J. Hydrol. 1964, 2, 116-123. [CrossRef]

20. Fu, B. On the calculation of the evaporation from land surface. Chin. J. Atmosph. Sci. 1981, 5, $23-31$.

21. Zhang, L.; Dawes, W.; Walker, G. Response of mean annual evapotranspiration to vegetation changes at catchment scale. Water Resour. Res. 2001, 37, 701-708. [CrossRef]

22. Dunne, T.; Richard, D. An experimental investigation of runoff production in permeable soils. J. Water Resour. Res. 1970, 6, 478-490. [CrossRef]

23. Rui, X.; Gong, X.; Zhang, C. Formation and calculation of watershed runoff yield. J. Hydroelectr. Eng. 2009, 28, 146-156.

24. Barthold, F.; Woods, R. Stormflow generation: A meta-analysis of field evidence from small, forested catchments. J. Water Resour. Res. 2015, 51, 3730-3753. [CrossRef] 
25. Kohler, M.A.; Linsley, R.K. Predicting the Runoff from Storm Rainfall; US Department of Commerce, Weather Bureau: Washington, DC, USA, 1951; p. 34.

26. Hu, C.; Li, S.; Zhang, W.; Chen, X.; Wang, J. Establishing and Testing Runoff Model Based on Runoff Coefficient. J. China Hydrol. 2016, 36, 8-13.

27. Pasquino, V.; Saulino, L.; Pelosi, A.; Allevato, E.; Rita, A.; Todaro, L.; Saracino, A.; Chirico, G. Hydrodynamic behaviour of European black poplar (Populus nigra L.) under coppice management along Mediterranean river ecosystems. J. River Res. Appl. 2018, 34, 586-594. [CrossRef]

28. Zhan, C.; Jiang, S.; Sun, F. Quantitative contribution of climate change and human activities to runoff changes in the Wei River basin, China. Hydrol. Earth Syst. Sci. 2014, 18, 8. [CrossRef]

29. Wang, S.; Yan, Y.; Yan, M.; Zhao, X. Quantitative estimation of the impact of precipitation and human activities on runoff change of the Huangfuchuan River Basin. J. Geogr. Sci. 2012, 22, 906-918. [CrossRef]

30. Liu, X. The Cause of the Sharp Decline of Water and Sediment in the Yellow River in Recent Years; Science Press of China: Beijing, China, 2016; pp. 45-69.

31. Meerkerk, A.; Wesemael, B.; Bellin, N. Application of connectivity theory to model the impact of terrace failure on runoff in semi-arid catchments. J. Hydrol. Process. 2009, 23, 2792-2803. [CrossRef]

32. Li, E.; Mu, X.; Zhao, G.; Gao, P.; Sun, W. Effects of check dams on runoff and sediment load in a semi-arid river basin of the Yellow River. Stoch. Environ. Res. Risk Assess. 2016, 31, 1791-1803. [CrossRef]

33. Lee, K.; Huang, J. Runoff simulation considering time-varying partial contributing area based on current precipitation index. J. Hydrol. 2013, 486, 443-454. [CrossRef]

34. Mo, S.; Gong, Y.; Li, J. Impact of human activities on flood process in Chabagou basin of the Loess Plateau, China. J. Basic Sci. Eng. 2019, 27, 492-508.

35. Zuo, D.; Xu, Z.; Yao, W.; Jin, S.; Xiao, P.; Ran, D. Assessing the effects of changes in land use and climate on runoff and sediment yields from a watershed in the loess plateau of china. J. Sci. Total Environ. 2016, 544, 238-250. [CrossRef]

36. Bergkamp, G. A hierarchical view of the interactions of runoff and infiltration with vegetation and microtopography in semiarid shrublands. J. Catena 1998, 33, 201-220. [CrossRef]

37. Guo, Y.; Liu, S.; Baetz, B. Probabilistic rainfall-runoff transformation considering both infiltration and saturation excess runoff generation process. J. Water Resour. Res. 2012, 48, 6513.

38. Kou, M.; Garcia, P.; Hu, S.; Jiao, J. The effect of Robinia pseudoacacia afforestation on soil and vegetation properties in the loess plateau (China): A chronosequence approach. J. For. Ecol. Manag. 2016, 375, 146-158. [CrossRef]

39. Jian, S.; Zhao, C.; Fang, S.; Yu, K.; Peng, S. Characteristics of rainfall interception by Caragana korshinskii and Hippophae rhamnoides in Loess Plateau of Northwest China. J. Appl. Ecol. 2012, 23, 2383-2389.

40. Li, N. Study on the Mechanism of Runoff Production and Confluence in the Loess Plateau under the Change of Underlying Surface. Ph.D. Thesis, Zhengzhou University, Zhengzhou, China, 2018.

41. Mascha, J.; Nadine, W.; Christian, P.; Matthias, S.; Christoph, L.; Frank, M.; Thomas, F. Nutrient release from decomposing leaf litter of temperate deciduous forest trees along a gradient of increasing tree species diversity. J. Soil Biol. Biochem. 2009, 41, 2122-2130.

(C) 2020 by the authors. Licensee MDPI, Basel, Switzerland. This article is an open access article distributed under the terms and conditions of the Creative Commons Attribution (CC BY) license (http://creativecommons.org/licenses/by/4.0/). 